Peningkatan Kemampuan Belajar... (Devy Anggraeni, Heni Pujiastuti)

\title{
PENINGKATAN KEMAMPUAN BELAJAR SISWA MENGGUNAKAN ALAT PERAGA DEKAK-DEKAK DI SDN PABUARAN 2 KOTA TANGERANG
}

\author{
Oleh: Devy Anggraeni, Heni Pujiastuti \\ (Mahasiswa dan Dosen Universitas Sultan Ageng Tirtayasa Serang) \\ Email: anggraenidevy3@gmail.com
}

\begin{abstract}
Abstrak
Matematika merupakan pelajaran yang dianggap sulit oleh siswa, maka untuk mengoptimalkan pembelajaran matematika pada materi KPK dan FPB siswa kelas IV SDN Pabuaran 2 yang berada di kota Tangerang digunakanlah alat peraga matematika yaiu dekak-dekak. Penelitian ini merupakan penelitian tindakan kelas. Perlakuan yang digunakan berawal dari perencanaan, pelaksanaan, observasi, kemudian refleksi. Subjek penelitian yaitu siswa kelas IV di SDN Pabuaran 2 kota Tangerang yang berjumlah 20 orang. Sumber data yang diperoleh melalui tes awal, tes akhir, observasi, dan wawancara. Materi yang digunakan dalam tindakan kelas yaitu KPK dan FPB. Tes awal yang dilakukan sebelum menggunakan dekak-dekak yaitu 11,54\%, sedangkan setelah menggunakan alat peraga dekak-dekak ada peningkatan mencapai 84,62\%, kemudian hasil proses kegiatan guru presentase rata-rata 89,09\%. Hasil observasi terhadap kegiatan siswa presentase rata-ratanya 85,4\%. Dapat disimpulkan bahwa kemampuan belajar matematika pada materi KPK dan FPB di kelas IV SD Negeri Pabuaran 2 kota Tangerang meningkat menggunakan alat peraga dekak-dekak.
\end{abstract}

Kata Kunci: Dekak-dekak, Alat Peraga, Kemampuan Belajar.

\section{IMPROVEMENT OF STUDENT LEARNING ABILITIES USING APPROACH TOOLS IN SDN PABUARAN 2 KOTA TANGERANG}

\begin{abstract}
Mathematics is a subject that is considered difficult by students, so to optimize the learning of mathematics in the material of the KPK and FPB grade IV SDN Pabuaran 2 students in the city of Tangerang used mathematical teaching aids. This research is a qualitative study and through class action. The treatment used starts from planning, implementing, observing, then reflecting. The research subjects were all grade IV students at SDN Pabuaran 2, Tangerang city, totaling 20 people. Sources of data obtained through preliminary tests, final tests, observations, and interviews. The material used in class actions is the KPK and FPB. Initial tests conducted before using the decks were $11.54 \%$, whereas after using the decks props there was an increase reaching $84.62 \%$, then the results of the teacher activity process an average percentage of $89.09 \%$. The results of observations on student activity averaging $85.4 \%$. It can be concluded that the
\end{abstract}


ability to learn mathematics in the material of the KPK and FPB in grade IV SD Negeri Pabuaran 2 in Tangerang increased using props.

Keywords: Dekak-Dekak, Teaching Aids, Study Skills.

\section{A. PENDAHULUAN}

Pada dasarnya matematika merupakan salah satu mata pelajaran yang kurang disukai oleh peserta didik, karena matematika dianggap suatu materi pelajaran yang sulit, serta terkadang kegiatan belajar mengajarnya pun kurang mengesankan. Masalah yang sering terjadi adalah siswa tidak dapat memahami konsep untuk menyelesaikan suatu permasalahan yang diberikan. Pemecahan masalah merupakan suatu tujuan pembelajaran yang utama, karena dalam proses pemecahan masalah siswa dapat memperoleh pengalaman serta dapat mengembangkan daya fikirnya dalam menyelesaikan masalah.

Demikian pula dalam materi KPK(Kelipatan Persekutuan Terkecil) dan FPB (Faktor Persekutuan Terbesar) harus dikuasai oleh siswa agar dapat memecahkan permasalahan secara efektif. Namun selama ini penyelesaian KPK dan FPB di sekolah masih menggunakan cara yang membuat siswa menjadi jenuh dan merasa kurang menarik, penyelesaian yang diajarkan guru di sekolah dalam materi KPK dan FPB selalu menggunakan pohon faktor atau dengan faktorisasi prima. Dikarenakan belum optimalnya kemampuan belajar siswa dalam materi KPK dan FPB di SD Negeri Pabuaran 2 kota Tangerang maka peneliti tertarik untuk melakukan pembelajaran pada siswa dibantu menggunakan alat peraga dekakdekak (Marzuki, 2015, Pratiwi, 2019) karena menurut peneliti permasalahan matematika memiliki banyak cara untuk menyelesaikannya.

Tenaga pendidik harus terus mengembangkan sistem pembelajaran yang inovatif, aktif, dan menyenangkan untuk dapat meningkatkan kemampuan belajar siswa, sehingga peserta didik tidak lagi merasa bahwa materi matematika membuat kejenuhan. Dalam proses belajar, siswa 10\% akan menangkap pelajaran dari apa yang dibaca, 20\% melalui pendengaran, 30\% dari penglihatan, 50\% 
melalui apa yang dilihat dan didengar, $70 \%$ melalui perkataan, dan $90 \%$ melalui apa yang dilakukan dan dikatakan (Dryden \& Jeannette, 2000).

Berdasarkan pernyataan tersebut maka peneliti tertarik melakukan pembelajaran menggunakan alat peraga dekak-dekak. Berdasarkan latar belakang permasalahan tersebut maka tujuan dari penelitian ini adalah untuk meningkatkan kemampuan belajar siswa di SD Negeri Pabuaran 2 kota Tangerang untuk memecahkan permasalahan matematika KPK dan FPB menggunakan alat peraga dekak-dekak.

\section{B. METODOLOGI PENELITIAN}

Penelitian yang digunakan menggunakan pendekatan kualitatif, yang bersifat deskriptif tanpa menggunakan analisis statistik, data serta hasil dipaparkan menggunakan kata-kata yang sesuai dengan kejadian yang dilakukan dalam proses penelitian yang dianalisis secara induktif. Jenis penelitian yang digunakan merupakan penelitian tindakan kelas. Hal ini dikarenakan dalam proses penelitian ini peneliti terlibat langsung dalam prosesnya bertindak sebagai instrument utama (Usman, 2008).

\section{HASIL PENELITIAN DAN PEMBAHASAN}

\section{Hasil sebelum mengunakan alat peraga}

Sebelum melakukan tindakan kelas dengan menggunakan alat peraga, peneliti membuat tes awal dengan memberikan 5 soal secara acak di papan tulis, dari 20 siswa hanya sedikit siswa yang bisa menjawab dengan cepat dan benar. Sedangkan yang lainnya tidak tuntas atau tidak menvcapai KKM yang telah ditentukan yaitu $<65$.

\section{Hasil setelah menggunakan alat peraga}

Dalam melaksanakan tindakan kelas menggunakan alat peraga peneliti mengawali dengan memberikan sedikit materi tentang KPK dan FPB, kemudian mendemonstrasikan alat peraga dekak-dekak sebelum siswa mengerjakan LKS. Siswa dibagi menjadi 5 kelompok untuk mengerjakan 
LKS. Kegiatan belajar mengajar saat tindakan kelas difokuskan pada menemukan hasil KPK dan FPB dari 2 bilangan, peneliti berperan langsung sebagai guru atau pembimbing dalam kelas.

Setelah semua siswa dengan masing-masing kelompoknya menyelesaikan LKS, peneliti meminta perwakilan kelompok untuk menjelaskan hasil LKS nya serta mendiskusikannya dengan kelompok lain. Selanjutnya setelah istirahat peneliti mengadakan tes akhir. Tes akhir diawasi oleh oleh wali kelas agar hasil tes tidak ada kerjasama antar siswa.

Kemudian berdasarkan hasil tes yang telah dilakukan siswa yang mendapatkan nilai > 65 sebanyak 16 siswa, sedangkan 4 siswa mendapatkan skor $<65$. Hasil tes akhir mencapi keberhasilan sebanyak 84,62\%. Maka dari itu sesuai dengan kriteria yang sudah ditetapkan, apabila $80 \%$ siswa mendapat skor $>65$, maka hasil tes dinyatakan tuntas.

Observasi dilakukan oleh 2 pengamat yaitu peneliti dan wali kelas. Berdasarkan hasil pengamatan terhadap aktivitas guru mencapai 89,09\%. Sedangkan hasil observasi peneliti terhadap siswa kelas IV SD Negeri Pabuaran 2 kota Tangerang mencapai rata-rata $85,4 \%$. Maka dengan hasil yang diperoleh tersebut hasil observasi adalah baik.

Kemudian hasil wawancara dengan 3 orang siswa untuk mengetahui sejauh mana pemahaman konsep yang mereka pahami setelah kegiatan belajar tersebut terhadap materi KPK dan FPB dengan menggunakan alat peraga dekak-dekak. Hasil wawancara dari 3 siswa bahwa siswa merasa senang dan merasa jauh lebih mudah memahami konsep pada materi KPK dan FPB, niali meereka pun meningkat dengan signifikan.

\section{PEMBAHASAN}

Alat peraga dekak-dekak berguna sebagai media pembelajaran dalam materi KPK dan FPB untuk membuat siswa lebih memahami lagi konsep yang diberikan oleh guru. Dekak-dekak merupakan alat peraga yang berfungsi sebagai 
permodelan bilangan secara konkrit, dapat pula sebagai alat untuk mencari deretan bialangan bulat (Yuniati, 2012).

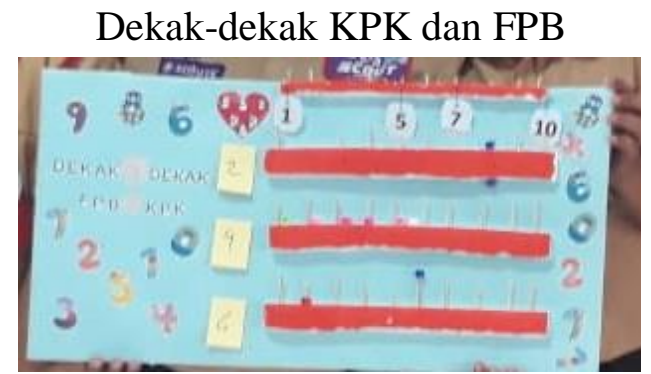

Gambar 1. Dekak-dekak KPK dan FPB

Berdasarkan hasil dan tujuan peneliti terhadap peningkatan kemampuan belajar siswa di SDN Pabuaran 2 kota Tangerang melalui test sebelum menggunakan alat peraga, test menggunakan alat peraga, serta wawancara terhadap beberapa siswa yang dipilih secara acak, bahwa terbukti ada peningkatan kemampuan belajar menggunakan alat peraga dekak-dekak sesuai dengan pernyataan dari Dryden \& Jeannette, 2000 Yang menyatakan : Dalam proses belajar, siswa $10 \%$ akan menangkap pelajaran dari apa yang dibaca, 20\% melalui pendengaran, $30 \%$ dari penglihatan, 50\% melalui apa yang dilihat dan didengar, $70 \%$ melalui perkataan, dan 90\% melalui apa yang dilakukan dan dikatakan. Dengan adanya alat peraga dekak-dekak siswa dapat mengalami proses belajar dari apa yang dibaca, pendengaran, penglihatan, perkataan (petunjuk), dan apa yang dilakukan.

\section{SIMPULAN}

Dari hasil penilaian tes awal hingga tes akhir menggunakan dekak-dekak memiliki rentang nilai yang sangat signifikan. Sebelum belajar menggunakan alat peraga dekak-dekak presentasenya 11,54\%, kemudian setelah belajar menggunakan alat peraga dekak-dekak presentase menjadi 84,62\%. Maka hasil tes sesuai dengan ketetapan kriteria yang diberikan oleh guru. Kemudian hasil observasi pun termasuk kedalam kategori baik. 
Pembelajaran dengan menggunakan alat peraga dekak-dekak terbukti dapat meningkatkan kemampuan belajar siswa dalam pemahaman konsep pada materi KPK dan FPB.

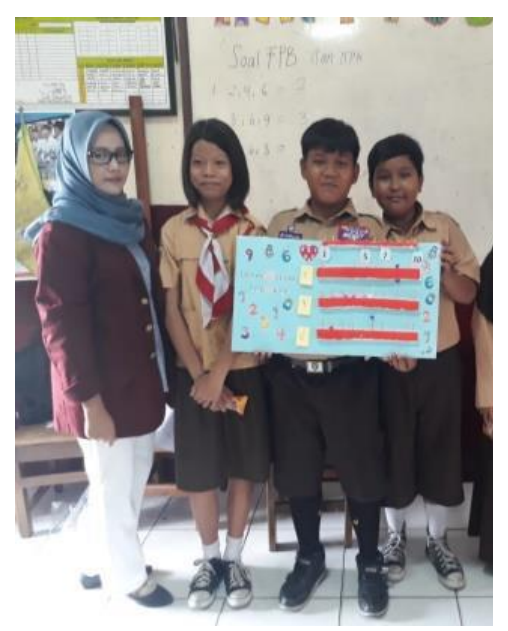

Gambar 2. Siswa yang diwawancarai

\section{DAFTAR PUSTAKA}

Dryden, Gordon dan Jeannette Vos. (2000). Revolusi Cara Belajar. Bandung: Kaifa.

Marzuki. (2015). “Prestasi Belajar Kelipatan Persekutuan Terkecil Dan Faktor Persekutuan Terbesar Dengan Mengunakan Alat Bantu Dekak-Dekak Pada Siswa Kelas Iv Sd Negeri 4 Bireuen”. JUPENDAS. Vol. 2 (1).

Usman dkk. (2008). Penelitian Tindakan Kelas. Banda Aceh: FKIP Unsyiah.

Yuniati, Suci. (2012). "Menentukan Kelipatan Persekutuan Terkecil (Kpk) Dan Faktor Persekutuan Terbesar (Fpb) Dengan Menggunakan Metode Pebi”. BETA. Vol. 2 (2), pp: 149-165.

Pratiwi, Norma. (2019). "Peningkatan Hasil Belajar Matematika Materi FaktorPersekutuan Terbesar (Fpb) Dan Kelipatan PersekutuanTerkecil (Kpk) Melalui Model Pembelajaran LectureBingo Dan Media Dekak Pada Siswa Kelas IvDi Mi Darul Falah Tawang O2Kecamatan Susukan Kabupaten SemarangTahun Pelajaran 2018/2019”. Skripsi. Salatiga: Institut Agama Islam Negeri Salatiga. 